\title{
3 Research Square

\section{Willingness to pay for breast cancer screening by providing basic and more complete information}

Maryam Moeeni

Isfahan University of Medical Sciences

Shiva Rahmani

Tabriz University of Medical Sciences

Mahmood Yousefi

Tabriz University of Medical Sciences

Shirin Nosratnejad ( $\nabla$ sh_nosratnejad@yahoo.com )

Tabriz University of Medical Sciences

\section{Research Article}

Keywords: Willingness to pay, Breast cancer, Contingent valuation method

Posted Date: July 30th, 2021

DOI: https://doi.org/10.21203/rs.3.rs-663415/v2

License: (c) (i) This work is licensed under a Creative Commons Attribution 4.0 International License. Read Full License 


\section{Abstract \\ Background}

Mammography screening is the most sensitive and specific test that can be conducted along with the clinical examination for the early diagnosis of breast cancer. However, like other tests, mammography screening is not a perfect test and has some limitations. The purpose of the present study is to measure women's willingness to pay for breast cancer screening with mammography by providing them with basic and more complete information.

\section{Method:}

In this study, 450 women aged 35-55 years were assigned into two groups of equal numbers. The first group was provided only with the basic information on 225 women, while the other group was provided with more complete information. The double bounded dichotomous choice method was used to extract women's willingness to pay for mammography screening.

\section{Result}

The mean willingness to pay for breast cancer screening with mammography was estimated as $26.14 \$$ in the group receiving basic information and $21.41 \$$ in the group receiving complete information. The results of interval regression analysis reported age of woman at the time interview, her occupation status, her education status, whether or not she had complementary insurance, and her prior experience of mammography as correlates of willingness to pay for mammography screening.

\section{Conclusion}

The more women have knowledge about all aspects of mammography screening, the more they are ready to utilize it. The results suggest the women can balance the possible benefits of mammography screening against its demerits.

\section{Background:}

Breast cancer is the most common and fatal malignancy in women worldwide and is considered as one of the major concerns on women's health (1). According to the statistics released by the Ministry of Health and Medical Education (MoHME), breast cancer has been reported as the most common cancer among Iranian women, accounting for up to $18.9 \%$ of cancer cases diagnosed among women in this country (2). The highest incidence of breast cancer in Iran belongs to women aged 35-55 (3). 
World Health Organization (WHO) and the American Cancer Society (ACS) consider early diagnosis as the best way to control breast cancer (4). Besides, secondary prevention of breast cancer helps diagnose the disease in the early stages and prevent disease progression (5). According to the recommendation of the American Breast Cancer Society (ABCS), breast self-examination, mammography, and clinical breast examinations are three effective methods for secondary prevention of breast cancer (6). According to existing evidence, mammography screening is the most sensitive and specific test that can be conducted along with the clinical examination for the early diagnosis of breast cancer (7). However, like other medical tests, mammography screening is not a perfect test and suffers from some limitations (8).

Thus, it is essential to provide adequate information about all positive and negative aspects of screening programs to individuals being asked about willingness to pay for breast cancer screening. The information should include the limitations and risks of each screening program along with its advantages. It would help obtain the real and valid value of the screening program. Accordingly, the purpose of the present study is to measure and compare women's willingness to pay for screening with mammography in cases of providing basic and more complete information. In the present study, it is hypothesized that providing more complete information about mammography screening affects women's willingness to pay and participate in a screening program. These extracted monetary values help the policymakers to obtain a better understanding of social preference for the implementation of the mammography screening program in local or even national level (9). In the present study, the contingent valuation method is used to obtain the real value of mammography from the women's viewpoint.

\section{Methods}

\section{Data collection}

The data of the present cross-sectional survey were collected in fall 2017, in Tabriz city, Iran. Study participants were chosen through the multistage (cluster) sampling: The municipality of Tabriz was classified in three regions including south, north, and center regions. Within each region, a health complex center, given full registration of the target population, was randomly selected. A total of 450 women aged between 35-55 years old were randomly selected from a registered individual and were further divided randomly into two groups of 225 individuals. Women assigned in one group received general information, while the others received general and also more complete information. Structured interviews were conducted by one author (SHM) inside the health complex centers. Participation in the interviews was voluntary. First, each woman was informed and assured that their privacy would be preserved in all stages of the research. After that, she was requested to provide verbal informed consent. Our study was also approved by the ethics committee at Tabriz University of Medical Sciences (ethical cone: IR.TBZMED.REC.1395.1067). Each interview lasted approximately 10 to 15 minutes.

\section{Information about breast cancer screening with mammography}


The general information provided to the first group of women included breast cancer epidemiology, global risky age of getting breast cancer, the average age of breast cancer incidence among women in Iran, and the advantages of mammography. The 225 women in the other group received more complete information including the probable disadvantages of mammography (such as false-negative mammography results) alongside the mentioned basic information.

\section{Questionnaire}

The structured questionnaire for this study was designed according to the guideline of the Contingent Valuation (CV) framework. The validity and reliability of the CV questionnaire have been confirmed repeatedly. The questionnaire consisted of four modules. Module 1 introduced the purpose of our study. Module 2 described separately two hypothetical scenarios including general and complete information about breast cancer screening with mammography. An additional Word file shows this in more detail [see Additional file 1]. The scenarios were followed by bids submitted to respondents. The starting bids valuing of $5 \$, 17 \$, 27 \$, 39 \$$, and $64 \$$ were submitted randomly to respondents regardless of whether respondents assigned to the first or second study group. To avoid starting point bias, lower and upper bids were determined by open-ended questions performed on the pilot sample of 30 women. Module 3 and Module 4 focused correspondingly on women's health status and socio-demographic information.

\section{Willingness to pay analyses}

The double bounded dichotomous choice methods was used to separately extract the willingness to pay for mammography screening among sample women receiving basic and complete information. The interval regression analysis was used to examine the correlates of willingness to pay for mammography screening.

\section{Results}

\section{Descriptive statistics}

The main characteristics of the participants are presented in Table 1. The average age of the participants was 42 years. They were mostly living in middle or low-income households. All women reported to have a basic health insurance enrollment, but just $13 \%$ had complementary health insurance. One-fourth of respondent women reported past-hospitalization, and more than $90 \%$ reported they had good or average health status. One fifth reported familial breast cancer history.

The average amount of willingness to pay for breast cancer screening with mammography was estimated to be $26.14 \$$ in the group receiving basic information and $21.41 \$$ in the group receiving more complete information.

As illustrated in Table 2, the willingness to pay for mammography screening in the group of women receiving more complete information was less compared to that of the group receiving only the basic information. 
The results of interval regression analysis of willingness to pay for mammography screening reported age of woman at the time interview, her occupation status, her education status, whether or not she obtained complementary health insurance, and her prior experience of mammography as correlates of willingness to pay for mammography screening. In more detail, younger, employed and more educated women, those women having complementary insurance, as well as those having prior experience of mammography were more likely to pay for mammography screening (Table 3 ).

\section{Discussion}

In the present study, applying the DBDC technique, it was tried to measure women's willingness to pay for breast cancer mammography given the types of information they receive about that screening. The findings can particularly help policymakers understanding the preferences of the women for preventing breast cancer.

Based on the obtained results, women receiving more complete information about mammography were willing to pay less for screening. It might support that the economic value of screening with mammography decline from the viewpoint of women, as they are aware of the not-complete accuracy of mammography tests mainly the possibility of a false positive. Hideo Yasunaga reported the similar finding for the willingness to pay for mass screening for prostate cancer (10). It seems that clinicians, health providers and health consultant should consider all concerns of women while providing them with medical information.

The result of the relationship between the socioeconomic conditions and willingness to pay for mammography screening can differ among different societies due to the differences in norms and structures of each particular society. In the present study, it was revealed that WTP for screening raised with the age of the women. This finding is consistent with some previous evidence (11-13). However, there is existing literature reporting the reverse $(14,15)$. Women sample in this study aged $35-55$ years old. In this specific age range, older women are potentially at higher risk of breast cancer. Therefore, they show more preference for mammography screening due to their own concerns about their health or suggestion of clinicians and health providers.

It was interesting that employed women reveals significantly more WTP for screening. It seems that some women do not take any action to receive mammography services due to economic shortages or/and not being economically dependent. According to the results of the other study, $78.3 \%$ of women declared the high cost of mammography as the main reason for not undergoing it (16); It was also found that women obtaining complementary health insurance and employed women express significantly higher value for mammography screening. This result supports the role of insurance coverage on affordability of mammography screening. These results totally convey that promoting ability to pay can convince women for undergoing mammography screening.

As expected, education level of women were significantly associated with more reported WTP for mammography screening. Existing literature support this finding $(12,13,15)$ It might address the fact that 
more educated women assess more awareness and better knowledge of the role of diagnosis services mainly mammography screening in early detection of breast cancer.

The result also suggested the prior experience of breast cancer were positively correlated to the willingness to pay for mammography. This correlation may stem from the fact that women who underwent mammography screening have less fears about screening. Therefore, clinician and health provider can promote mammography screening by help women overcome their fears and concerns about screening procedure.

This study raises a concern; the data sample contains women with good variation in respect to demographic, economic, and health status condition. Still, since, a couple of population women were not willing to participate in the study, we did not access a completely random sample of population women. Therefore, this limitation must be considered when interpreting the results. However, this study had the considerable advantage of addressing how providing women with information about mammography screening could influence their decision about WTP for this helpful diagnostic test.

\section{Conclusion}

The results of our study indicate the more women are informed about adverse aspects of mammography screening, the less they would be ready to utilize it. In this way, women can balance the possible disadvantages of mammography screening against its merits. However, women with different characteristics might value mammography screening in different ways.

\section{Declarations}

\section{Ethics approval and consent to participate}

It is confirmed that informed consent was obtained from all participants. It is also confirmed that all methods were carried out in accordance with relevant guidelines and regulations. Moreover, all stages of the current study were ethically reviewed and approved by the ethics board of Tabriz University of Medical sciences. The ethical code is IR.TBZMED.REC.1395.1067.

\section{Consent for publication}

Not applicable

\section{Availability of data and material}

The datasets generated and analysed during the current study are not publicly available due to lack of permission from the Tabriz University of Medical sciences, but are available from the corresponding author on reasonable request.

\section{Competing interests}


The authors declare that they have no competing interests.

\section{Funding}

The authors received no specific funding for this paper.

\section{Authors' contributions}

Conceptualization: SN and SR; Methodology: SN, SR, MM and MY; Data collection: SR.; Formal analysis: MM, SN SR; Validation, MM, SN; Writing Original Draft: MM, SN SR; Writing Review and Editing: all authors; Supervision: S.N.

\section{Acknowledgements}

This work was supported by the Tabriz University of Medical Sciences. We really appreciate the support. We also thank all participants for their contributions to this study.

\section{Additional file}

File name: Additional file1

File format: DOCX

Title of data: Appendix 1

Description of data: This file contains two Hypothetical scenarios describing general information about breast cancer screening with mammography

\section{Abbreviations}

MoHME, WHO, ACS, ABCS, SHM, CV, WTP

\section{References}

1. Ferlay J, Soerjomataram I, Dikshit R, Eser S, Mathers C, Rebelo M, et al. Cancer incidence and mortality worldwide: sources, methods and major patterns in GLOBOCAN 2012. International journal of cancer. 2015;136(5):E359-E86.

2. Nafissi N, Khayamzadeh M, Zeinali Z, Pazooki D, Hosseini M, Akbari ME. Epidemiology and histopathology of breast cancer in Iran versus other Middle Eastern countries. Middle East Journal of Cancer. 2018;9(3):243-51.

3. Besharat S, Motie MR, Besharat M, Roshandel G. Breast cancer risk factors in women of Golestan Province in Iran: A case-control study. The Iranian Journal of Obstetrics, Gynecology and Infertility. 
2011;13(6):46-51.

4. Oeffinger KC, Fontham ET, Etzioni R, Herzig A, Michaelson JS, Shih Y-CT, et al. Breast cancer screening for women at average risk: 2015 guideline update from the American Cancer Society. Jama. 2015;314(15):1599-614.

5. Sakurai H. THE CANCER SCREENING PROGRAM IN JAPAN: ITS PRESENT STATE AND FUTURE PROSPECTS. Asian Medical Journal. 1999;42(8):343-8.

6. Godavarty A, Rodriguez S, Jung Y-J, Gonzalez S. Optical imaging for breast cancer prescreening. Breast Cancer: Targets and Therapy. 2015;7:193.

7. Hicks MJ, Davis JR, Layton JM, Present AJ. Sensitivity of mammography and physical examination of the breast for detecting breast cancer. Jama. 1979;242(19):2080-3.

8. Statistics V. Statistics and Information Department, Minister's Secretariat, Ministry of Health, Labour and Welfare, Japan. 2009.

9. Nosratnejad S, Rashidian A, Mehrara M, Sari AA, Mahdavi G, Moeini M. Willingness to pay for social health insurance in Iran. Global journal of health science. 2014;6(5):154.

10. Yasunaga $\mathrm{H}$. Willingness to pay for mass screening for prostate cancer: a contingent valuation survey. International Journal of Urology. 2008;15(1):102-5.

11. Yasunaga $\mathrm{H}$, Ide $\mathrm{H}$, Imamura $\mathrm{T}$, Ohe $\mathrm{K}$. Women's anxieties caused by false positives in mammography screening: a contingent valuation survey. Breast cancer research and treatment. 2007;101(1):59-64.

12. Khaliq W, Harris CM, Landis R, Bridges JF, Wright SM. Hospitalized women's willingness to pay for an inpatient screening mammogram. The Annals of Family Medicine. 2014;12(6):556-8.

13. Wagner TH, Hu T-w, Dueñas GV, Pasick RJ. Willingness to pay for mammography: item development and testing among five ethnic groups. Health Policy. 2000;53(2):105-21.

14. Wagner TH, Hu T-w, Duenas GV, Kaplan CP, Nguyen BH, Pasick RJ. Does willingness to pay vary by race/ethnicity? An analysis using mammography among low-income women. Health Policy. 2001;58(3):275-88.

15. Clarke PM. Valuing the benefits of mobile mammographic screening units using the contingent valuation method. Applied Economics. 2000;32(13):1647-55.

16. Tavakolian L, Boniadi F, Malekzadeh E. The investigation of factors associated with breast cancer screening among Kazeroon women aged 20-65 in 2013. Nurs J Vulnerable. 2015;1(1):17-31.

\section{Tables}

Table 1. Sample's descriptive statistics $(n=450)$ 


\begin{tabular}{|ll|}
\hline Variable name & Mean/percentage \\
\hline Monthly household income & \\
Low (<246.60\$) & $56.85 \%$ \\
Medium (246.60 - 739.82) & $34.75 \%$ \\
High (>739.82) & $8.4 \%$ \\
\hline Age of woman & 42 \\
\hline Education & \\
\hline Illiterate & $8 \%$ \\
\hline Up to nine years of schooling & $54 \%$ \\
high school degree & $23 \%$ \\
College degree & $15 \%$ \\
\hline Employment status & \\
\hline Employed & $13 \%$ \\
\hline Housewife & $87 \%$ \\
\hline Family size & 3.60 \\
\hline Marital status & \\
\hline Currently Married & $92 \%$ \\
\hline Single & $8 \%$ \\
\hline Having Supplementary insurance & $13 \%$ \\
\hline Past-hospitalization experience & $26 \%$ \\
\hline Past-mammography experience & $16 \%$ \\
\hline Health status (as self-report) & \\
Good & $50 \%$ \\
\hline Average & $43 \%$ \\
\hline Bad & $7 \%$ \\
\hline
\end{tabular}

Table 2. Calculated WTPs 


\begin{tabular}{|llllrr|}
\hline Scenario & WTP(\$) & Standard Error & \multicolumn{1}{l|}{$\mathrm{Cl}(95 \%)$} & \\
\hline Complete information & 21.41 & 2.21 & 16.76 & - & 25.64 \\
\hline basic information & 26.14 & 1.97 & 21.94 & - & 30 \\
\hline
\end{tabular}

Table 3. Correlates of WTP for mammography screening ( $N=450)$

\begin{tabular}{|c|c|c|c|}
\hline Variables & Model 1 & Model2 & Model3 \\
\hline Age of woman & $-0.26 * \star$ & $-0.24 * \star$ & $-0.28 * \star$ \\
\hline Married & -0.56 & -0.38 & -0.63 \\
\hline Employed & $8.27 * \star \star$ & $8.19 * \star \star$ & $8.10 * \star \star$ \\
\hline Education & Reference & Reference & Reference \\
\hline Less than diploma & $4.26^{\star \star}$ & $3.88 * *$ & 3.84 ** \\
\hline Diploma & $5.10 *$ & $4.65^{\star}$ & $5.12^{\star}$ \\
\hline \multicolumn{4}{|l|}{ University degree } \\
\hline Having supplementary insurance & $4.38 * \star$ & $4.23^{\star \star}$ & $3.83^{\star *}$ \\
\hline Health status & - & Reference & Reference \\
\hline Bad / Medium health & & 0.86 & 0.72 \\
\hline \multicolumn{4}{|l|}{ Good health } \\
\hline Familial history of cancer & - & 1.68 & 0.97 \\
\hline prior experience of mammography & - & - & $2.85^{\star}$ \\
\hline$* p<0.1, * * p<0.05, * \star * p<0.01$ & & & \\
\hline
\end{tabular}

\section{Supplementary Files}

This is a list of supplementary files associated with this preprint. Click to download.

- Additionalfile1.docx 